\title{
Study the efficacy of cyproterone and metformin in modulation of hormonal disturbances in estrogen valerate induced PCOS in female rats
}

\author{
Wajdy Jabbar Majid 1, ${ }^{*}$, Tayseer Ali Talab ${ }^{2}$ and Muslim Nahi Saeed 3 \\ ${ }^{1}$ Department of Biochemistry, Thi-Qar Medical College, University of Thi-Qar, Iraq. \\ 2 Department of Pharmacology, Thi-Qar Medical College, University of Thi-Qar, Iraq. \\ ${ }^{3}$ Department of Community Medicine, Thi-Qar Medical College, University of Thi-Qar, Iraq.
}

International Journal of Biological and Pharmaceutical Sciences Archive, 2021, 02(01), 055-058

Publication history: Received on 02 July 2021; revised on 02 August 2021; accepted on 04 August 2021

Article DOI: https://doi.org/10.53771/ijbpsa.2021.2.1.0068

\begin{abstract}
Polycystic ovarian syndrome (PCOS) is an endocrine disorder affecting women in child bearing age and is considered the main cause of infertility. This study aims to determine the efficacy of cyproterone $12 \mathrm{mg} / \mathrm{kg}$ and metformin 50 $\mathrm{mg} / \mathrm{kg}$ as a single oral daily dose for 20 days, in PCOS induced in female rats by estrogen valerate. In untreated group PCOS, the level of serum luteinizing hormone ( $\mathrm{LH})$ and follicle-stimulating hormone (FSH) was significantly $(\mathrm{P}<0.0001)$ decrease, while estradiol and testosterone levels were increased significantly ( $\mathrm{P}<0.0001$ and $\mathrm{P}<0.001$ respectively) in comparison with control group. Both cyproterone and metformin significantly increased LH and FSH levels (P<0.05) compared to the untreated PCOS group. Both cyproterone and metformin reduced the level of estradiol hormone significantly $(\mathrm{P}<0.001$ and $\mathrm{P}<0.05$, respectively). Cyproterone also decreased the level of testosterone $(\mathrm{P}<0.0001)$ compared to the untreated PCOS group, and the testosterone level became less than that recorded in the control group $(\mathrm{P}<0.05)$, Metformin also significantly decreased the level of testosterone compared to the untreated PCOS group (P $<0.01$ ), but it still more than that in control. According to the results of the current study, we can conclude that cyproterone and metformin showed an efficacy in the treatment of PCO, and can restore the normal hormonal levels and should be considered in the treatment of this disease.
\end{abstract}

Keywords: PCOS; Rats; Induction; Estrogen valerate; Cyproterone; Metformin

\section{Introduction}

Polycystic ovarian syndrome (PCOS) is an endocrine disorder affecting women in child bearing age and is considered the main cause of infertility as a result of anovulation [1-2]. According to Rotterdam ESHRE/ASRM-Sponsored PCOS Consensus Workshop Group (2003), PCOS is diagnosed by the presence of two of the three following diagnostic criteria: oligoamenorrhoea, polycystic ovaries morphology and hyper-androgenemia [3]. PCOS is the most common endocrine pathology in the reproductive-aged female around the world. The prevalence is greatly variable ranging from $2.2 \%$ to as high as $26 \%$ [4]. Symptoms can vary from mild to severe conditions. The common symptoms of PCOS included acne (occur after adolescence and does not respond to usual treatment), rapid weight gain, difficulty in losing weight, hirsutism, mental health problems, metabolic dysfunction, difficulty getting pregnant, thinning hair and hair loss from the head, oily skin, depression and mood changes, patches of thickened velvety, darkened skin on the neck, arms, breast or thighs Acanthus's nigricans, pelvic pain and obesity (80\% of women with PCOS are obese) [5-6]. PCOS develops when the ovaries are stimulated to produce excessive amounts of male hormones (androgens), especially testosterone, by either the release of excessive luteinizing hormone from the anterior pituitary gland, elevated level of insulin in the blood (hyper-insulinaemia) in women whose ovaries are sensitive to this stimulus or reduced levels of sex-hormone binding globulin (SHBG) resulting in increased free androgens [7]. The majority of patients with PCOS have insulin

${ }^{*}$ Corresponding author: Wajdy Jabbar Majid

Department of Biochemistry, Thi Qar Medical College, University of Thi- Qar,Iraq.

Copyright $(2021$ Author(s) retain the copyright of this article. This article is published under the terms of the Creative Commons Attribution Liscense 4.0. 
resistance and/or obesity. Their elevated insulin levels contribute to disrupt all components of the hypothalamushypophysis-ovary axis, and ovarian tissue insulin resistance results in impaired metabolic signaling that lead to PCOS [8]. Hyper-insulinemia increases GnRH pulse frequency, LH over FSH dominance, increased ovarian androgen production, decreased follicular maturation and decreased SHBG binding [7]. Accordingly, this study was designed to determine the efficacy of cyproterone (anti-androgeneic drug) and metformin (which characterized by multiple hypoglycemic effect), in modulation of hormonal disturbances in PCOS induced in female rats.

\section{Material and methods}

Forty adult albino female rats of $250 \pm 10 \mathrm{~g}$ with regular estrus cycle were obtained from the animal house in Thi-Qar College of Science and adapted for 2 weeks on the experiment condition $\left(23 \pm 2^{\circ} \mathrm{C}, 14 \mathrm{hrs}\right.$ light/10 hrs dark) before the study. They were fed a standard rat diet and tap water ad libtum. The first ten animals were left without PCOS induction and were treated for 20 days with a normal saline. The rest thirty females were given a single intramuscular injection of $4 \mathrm{mg}$ estrogen valerate (Riedeldehaen, Germany) to induce PCOS [9-10]. After 30 days of induction of PCOS, the animals were divided into three groups (10 each) and treated respectively with cyproterone $12 \mathrm{mg} / \mathrm{kg}$, metformin 50 $\mathrm{mg} / \mathrm{kg}$ as a single oral dose daily, while the third group was given normal saline (the vehicle) $0.5 \mathrm{ml} / \mathrm{animal}$ to serve as negative control (PCO untreated group). The stage of the estrus cycle was determined by microscopic examination of vaginal smears [11]. At the end of the treatment period, the animals were killed by neck dislocation after chloroform anesthesia. The blood samples from the positive control and experimental groups were immediately obtained for hormonal analysis. All hormones were determined by enzyme-linked immunosorbent assay (ELISA, Kit CA-92627 Cod. No. EIA- 4K2G5, from American Co. Monobind, Inc. Costa Mesa).

Statistical differences were determined by student-t-test using SPSS.

\section{Results}

The level of serum LH and FSH was significantly $(\mathrm{P}<0.0001)$ decrease in PCOs untreated group, while estradiol and testosterone levels were increased significantly $(\mathrm{P}<0.0001$ and $\mathrm{P}<0.001$ respectively) in comparison with control group. Both cyproterone and metformin significantly increased LH and FSH levels $(\mathrm{P}<0.05)$ compared to the untreated PCOS group. However, the levels of both LH and FSH hormones were still significantly less than that recorded in control group $(\mathrm{P}<0.001)$. Cyproterone reduced the level of estradiol hormone significantly $(\mathrm{P}<0.001)$ compared with untreated PCOS group, but its level was still higher than that in the control group $(\mathrm{P}<0.05)$. Metformin also decreased estradiol hormone compared with untreated PCOS group ( $\mathrm{P}<0.05)$, but its level was still significantly more than that in control group ( $\mathrm{P}<0.001)$. It also decreased the level of testosterone $(\mathrm{P}<0.0001)$ compared to the untreated PCOS group, and the testosterone level became less than that recorded in the control group $(\mathrm{P}<0.05)$, Metformin also significantly decreased the level of testosterone compared to the untreated PCOS group $(\mathrm{P}<0.01)$, but it still more than that in control $(\mathrm{P}<0.05)$ (table 1).

Table 1 The effect of cyproterone and metformin on the serum levels of LH, FSH, estradiol and testosterone in PCO induced in female rats by estrogen valerate

\begin{tabular}{|l|c|c|c|c|}
\hline Groups & LH IU/ml & FSH IU/ml & Estradiol $\mathbf{~ g g / m l ~}$ & Testosterone $\boldsymbol{\mu g} / \mathbf{m l}$ \\
\hline Control & $1.465 \pm 0.32^{\mathrm{a}}$ & $1.232 \pm 0.17^{\mathrm{a}}$ & $26.87 \pm 2.11^{\mathrm{a}}$ & $0.047 \pm 0.016^{\mathrm{a}}$ \\
\hline PCO untreated & $0.362 \pm 0.10^{\mathrm{b}}$ & $0.262 \pm 0.08^{\mathrm{b}}$ & $118.12 \pm 5.06^{\mathrm{b}}$ & $0.142 \pm 0.018^{\mathrm{b}}$ \\
\hline PCOS treated with cyproterone & $0.322 \pm 0.16^{\mathrm{c}}$ & $0.278 \pm 0.06^{\mathrm{c}}$ & $38.62 \pm 3.32^{\mathrm{c}}$ & $0.028 \pm 0.022^{\mathrm{c}}$ \\
\hline PCOS treated with metformin & $0.342 \pm 0.18^{\mathrm{c}}$ & $0.286 \pm 010^{\mathrm{c}}$ & $86.62 \pm 13.04^{\mathrm{d}}$ & $0.082 \pm 0.012^{\mathrm{d}}$ \\
\hline \multicolumn{2}{|c|}{ Vertically, similar letter means not significant } \\
\hline
\end{tabular}

The cyclic rhythm of estrus cycle which disturbed in PCOS rat females was returned to normal in both cyproterone and metformin treated groups.

\section{Discussion}

Estrogen valerate methods of producing experimental PCOS models showed hormonal and histological findings mimicking that occurred in women [12]. Therefore, this model was used to induce PCOS in the current study. The declined levels of gonadotropins in PCO females in this study were in agreement with many previous studies and considered as a characteristic feature of PCO. Testosterone and estradiol possessed a central position in PCOS, their 
elevation was closely related to the ovarian pathology, and both hormones were used for induction of PCOS in animal models [13-15]. Neuro-endocrinological studies showed that the neuronal component responsible for the induction of the LH surge is located in the preoptic area which stimulated by estrogen [16-18]. The efficacy of metformin to restore the normal physiological status in this study was in agreement with many previous studies [14]. It was effective as a treatment for anovulatory infertility amongst women with PCOS [19]. It improved the weight gain, hormone profile and ovarian follicular cell architecture. It decreased LH, LH/FSH, tumor necrosis factor- $\alpha$ (TNF- $\alpha$ ) and tissue anti-müllerian hormone (AMH) levels which were induced in the PCOS group. It ameliorated the elevated number of secondary and atretic follicles and the decreased number of Graafian follicles in the PCOS group. Many authors mentioned that the effects attributed to antioxidant and anti-inflammatory effects of metformin [20-21]. Furthermore, insulin resistance plays a pivotal role in PCOS. Insulin-sensitizer agents such as metformin have been shown to improve the endocrine and metabolic aspects of PCOS [22]. So, part of metformin effects on PCOS could be attributed to its hypoglycemic and insulin-sensitizing effect [23].

On the other hands, many studies confirmed the efficacy of cyproterone in PCOS. Cyproterone significantly decreased the free androgen index (-81\%) and increased sex hormone binding globulin $(+639 \%)$ in women with PCOS [24]. The treatment with cyproterone resulted in marked clinical improvement. The basal plasma gonadotropin, estradiol, estrone, testosterone and androstenedione levels were significantly decreased [25-26]. The restoration of normal cyclic rhythm of estrus cycle in the current study were occurred as a result of restoration of the hormonal status, because the reproductive physiology including the steroidogenesis, the follicular development, ovulation and development and regression of corpora lutea were controlled by the cyclic production of pituitary hormones [18].

\section{Conclusion}

According to the results of the current study, we can conclude that cyproterone and metformin showed an efficacy in the treatment of PCO, and can restore the normal hormonal levels, normal ovarian histology and should be considered in the treatment of this disease.

\section{Compliance with ethical standards}

\section{Acknowledgments}

We acknowledged the dean of Thi-Qar College of medicine for the scientific support.

\section{Disclosure of conflict of interest}

The authors declare that there is no conflict of interest.

\section{Statement of ethical approval}

The study was approved by the ethical committee of Thi-Qar College of medicine. It performed on animals according to the regulations of the ethical committee of Thi-Qar University.

\section{References}

[1] Bellver J, Rodríguez-Tabernero L, Robles A, Muñoz E, Martínez F, Landeras J, García-Velasco J, Fontes J, Álvarez M, Álvarez C, Acevedo B. Group of interest in Reproductive Endocrinology (GIER) of the Spanish Fertility Society (SEF). Polycystic ovary syndrome throughout a woman's life. J Assist Reprod Genet. 2018; 35(1):25-39.

[2] de Melo AS, Dias SV, Cavalli Rde C, Cardoso VC, Bettiol H, Barbieri MA, Ferriani RA, Vieira CS. Pathogenesis of polycystic ovary syndrome: multifactorial assessment from the foetal stage to menopause. Reproduction 2015; 150(1): R11-24.

[3] Rotterdam ESHRE/ASRM-Sponsored PCOS consensus workshop group. Revised 2003 consensus on diagnostic criteria and long-term health risks related to polycystic ovary syndrome (PCOS). Hum Reprod. 2004; 19(1):4147.

[4] Kirthika SV, Paul J, Sudhakar S, Selvam PS, priya VS.Polycystic ovarian syndrome - Interventions for the emerging public health challenge: A scoping review.Drug Invention Today. 2019; 12(3): 398-401.

[5] Vrbíková J, Cibula D, Dvoráková K, Stanická S, Sindelka G, Hill M, Fanta M, Vondra K, Skrha J. Insulin sensitivity in women with polycystic ovary syndrome. J Clin Endocrinol Metab. 2004;89(6):2942-2945. 
[6] Moran LJ, Pasquali R, Teede HJ, Hoeger KM, Norman RJ. Treatment of obesity in polycystic ovary syndrome: a position statement of the androgen excess and polycystic ovary syndrome society. Fertil Steril. 2009; 92(6):19661982.

[7] Kabel AM. Polycystic ovarian syndrome: Insights into pathogenesis, diagnosis, prognosis, pharmacological and non-pharmacological treatment. J Pharma Reports. 2016;1(1): 103.

[8] Rojas J, Chávez M, Olivar L, Rojas M, Morillo J, Mejías J, Calvo M, Bermúdez V. Polycystic ovary syndrome, insulin resistance, and obesity: navigating the pathophysiologic labyrinth. Int J Reprod Med. 2014; 719050.

[9] Dăneasă A, Cucolaş C, Lenghel LM, Olteanu D, Orăsan R, Filip GA. Letrozole vs estradiol valerate induced PCOS in rats: glycemic, oxidative and inflammatory status assessment. Reproduction 2016;151(4):401-409.

[10] Venegas B, De León Gordillo LY, Rosas G, Espinoza JA, Morán C, Domínguez R, Morales-Ledesma L. In rats with estradiol valerate-induced polycystic ovary syndrome, the acute blockade of ovarian $\beta$-adrenoreceptors improve ovulation. Reprod Biol Endocrinol 2019;17(1):95.

[11] Al-Gazi ZS, Al-Snafi AE, Al-Abady FA. Effect of toxoplasmosis and/ or its treatment ( sulpadiazine and pyrimetamine) on female rats reproductive performance. Indian Journal of Pharmaceutical Science \& Research 2016; 6(1): 35-40.

[12] Singh KB. Rat models of polycystic ovary syndrome. Source book of models for biomedical research. Humana Press Inc, N J. 2008: 405-410.

[13] Fagius J. Sympathetic nerve activity in metabolic control-some basic concepts. Acta Physiol Scand. 2003; 177: 337-43.

[14] Al-Snafi AE. Study the efficacy of anti-estrogenic drugs in the treatment of poly cystic ovary induced in female rats by estrogen valerate. World J Pharm Sci. 2014; 2(4): 313-316.

[15] Farideh ZZ, Bagher M, Ashraf A, Akram A, Kazem M. Effects of chamomile extract on biochemical and clinical parameters in a rat model of polycystic ovary syndrome. J Reprod Infertil. 2010;11(3):169-74.

[16] Szukiewicz D, Uilenbroek JT. Polycystic ovary syndrome--searching for an animal model. J Med. 1998; 29(56):259-75.

[17] Chrousos GP. Regulation and dysregulation of the hypothalamic-pituitary-adrenal axis. The corticotropinreleasing hormone perspective. Endocrinol Metab Clin North Am. 1992;21(4):833-58.

[18] Malyala A, Kelly MJ, Rønnekleiv OK. Estrogen modulation of hypothalamic neurons: activation of multiple signaling pathways and gene expression changes. Steroids. 2005;70(5-7):397-406.

[19] Tang T, Lord JM, Norman RJ, Yasmin E, Balen AH. Insulin-sensitising drugs (metformin, rosiglitazone, pioglitazone, D-chiro-inositol) for women with polycystic ovary syndrome, oligo amenorrhoea and subfertility. Cochrane Database Syst Rev. 2012;(5):CD003053.

[20] Furat Rencber S, Kurnaz Ozbek S, Eraldemır C, Sezer Z, Kum T, Ceylan S, Guzel E. Effect of resveratrol and metformin on ovarian reserve and ultrastructure in PCOS: an experimental study. J Ovarian Res. 2018;11(1):55.

[21] Costello M, Shrestha B, Eden J, Sjoblom P, Johnson N. Insulin-sensitising drugs versus the combined oral contraceptive pill for hirsutism, acne and risk of diabetes, cardiovascular disease, and endometrial cancer in polycystic ovary syndrome. Cochrane Database Syst Rev. 2007;(1):CD005552.

[22] Fruzzetti F, Perini D, Russo M, Bucci F, Gadducci A. Comparison of two insulin sensitizers, metformin and myoinositol, in women with polycystic ovary syndrome (PCOS). Gynecol Endocrinol. 2017;33(1):39-42.

[23] Rena G, Hardie DG, Pearson ER. The mechanisms of action of metformin. Diabetologia. 2017;60(9):1577-1585.

[24] Villaseca P, Hormaza P, Cárdenas I, Oestreicher E, Arteaga E. Ethinylestradiol/ cyproterone acetate in polycystic ovary syndrome: lipid and carbohydrate changes. Eur J Contracept Reprod Health Care. 2004;9(3):155-165.

[25] Schaison G, Couzinet B. Comparative effects of cyproterone acetate or a long-acting LHRH agonist in polycystic ovarian disease. Horm Res. 1987;28(2-4):169-174.

[26] Couzinet B, Le Strat N, Brailly S, Schaison G. Comparative effects of cyproterone acetate or a long-acting gonadotropin-releasing hormone agonist in polycystic ovarian disease. J Clin Endocrinol Metab. 1986;63(4):1031-1035. 